\title{
University Students and Emotional Bargaining - a Comparative Study of Staff Perspectives in Northern Europe
}

\author{
Dr Brendan Bartram, \\ Institute of Education, \\ University of Wolverhampton, \\ Gorway Road, \\ Walsall, \\ WS1 3BD \\ UK
}

Email: b.bartram@wlv.ac.uk

\begin{abstract}
:
This paper examines lecturers' perspectives on students' 'emotional bargaining' in higher education (HE). Based on a social-functional understanding of emotions, it utilises a smallscale qualitative survey approach to explore and compare the views of 43 teaching staff at three universities in England, the Netherlands and Sweden. Particular consideration is given to staff perceptions of students' motives for engaging in such behaviour and the factors potentially driving it. Findings suggest broadly similar views are held by the respondents across the three settings, and staff views on potential 'solutions' are investigated. The study offers tentative evidence that the neo-liberal logics perceived to guide university policies and practices may be a central factor in engendering student bargaining behaviours, particularly in the English context, where neo-liberal regimes are arguably more pronounced. Finally, an attempt is made to identify a number of recommendations for institutional consideration and potential practice.
\end{abstract}

Key words: higher education; staff-student interactions; emotional bargaining; neoliberalism; student vulnerability 


\section{University Students and Emotional Bargaining - a Comparative Study of Staff Perspectives in Northern Europe}

\section{Introduction}

This paper builds on previous qualitative research carried out by the author (Bartram 2015) on university students' emotional bargaining or 'affective strategizing' (AS), by extending the focus to an examination of the views of staff working in higher education (HE) in three different European countries - England, the Netherlands and Sweden. The previous study was based on an analysis of student emails and staff interviews at one English university, and used a case-study approach to explore the nature of AS and the motivational drivers behind it - i.e. how and why students sometimes use their emotions as negotiating mechanisms. The findings indicated that AS was considered a common occurrence in day-to-day student-staff interactions, driven by an amalgam of socio-cultural and educational factors. The importance of a neo-liberal HE climate in engendering AS-behaviours emerged as a theme in the study. Informal feedback and responses received from $\mathrm{HE}$ teachers since publication suggested that the findings resonated strongly with many lecturers working at English institutions. These reactions led me to wonder whether the context of English HE, underpinned by high fees and neo-liberal methodologies, might mean that AS is a more conspicuous phenomenon here than elsewhere, particularly in countries where such ideologies might not (yet) be so pronounced. This thought prompted my interest in comparing the perspectives of lecturers working in different national settings, in an attempt to produce more nuanced insights into the phenomenon. The cross-cultural angle adopted here may thus contribute to our understanding of the extent to which (perceptions of) AS might be culturally mediated and inflected. 
This particular area of staff-student interactions is still relatively under-explored (Van Kleef, Homan and Cheshin 2012, Hagenauer, Gläser-Zikuda and Volet 2016), despite a number of researchers highlighting its worthwhileness some years ago. Barry et al (2004), Morris and Keltner (2006) and Smithey Fulmer, Barry and Long (2008), for example, all comment on the relative paucity of conceptual and empirical work on the tactical use of emotion. This article therefore offers a current, innovative and critical discussion of the phenomenon in a bid to address this imbalance and add to our knowledge of this field. It begins by exploring the theoretical basis of AS, locating it within a social-functional understanding of emotions. This is followed by a review of studies on the nature and place of emotion in late modern society in order to explore the broader societal background to AS, before examining the behaviour specifically within the HE context. After discussing the research approach adopted, the findings present a comparison of staff perspectives in order to address the paper's central aims of shedding light on AS-behavioural contexts (the emotional scenarios students draw on), the perceived motives and causes, and staff views on potential remedies. The following research questions were devised to support these aims and underpin the enquiry:

1. To what extent do teaching staff in the three countries share similar views on students' strategic use of emotion at university?

2. What educational recommendations might be gleaned from an analysis of their perspectives?

\section{Literature Review}

Firstly, it is important to establish what is meant here by the notion of affective strategizing. The concept draws on understandings derived from a number of psychological studies of emotion. Li and Roloff (2006), for example, refer to 'strategic emotion' in relation to 
bargaining situations where emotions can be deployed as influencing strategies. Barry (1999, 94) offers a similar usage, defining AS-related behaviours as "the wilful use of emotional display or expression as a tactical gambit by an individual negotiator". Such studies highlight the important role emotions can play in negotiations, defined by Barry, Smithey Fulmer and Van Kleef as "a form of contextualised social interaction” $(2004,73)$. Morris and Keltner $(2006,2)$ extend this analysis:

"Negotiators use emotions in order to... make demands, seek cooperation and seal commitments. Also, the dramatic emotional displays in high-stakes negotiations are but more extreme versions of the expressive performances required by the more mundane conflicts that people face in everyday interactions."

The authors discuss the variety of ways in which emotions - "whether genuine expressions or strategic displays" (p.4) can help to facilitate negotiations and move interactions forward. This last point is an important one because it highlights a problematic set of questions in relation to AS - when confronted with someone's 'emotional display,' how do we know if 1) this is simply a genuine or natural expression of felt emotion, devoid of negotiative intention; or 2) it is a (strategic) expression of genuine or 'inauthentic' emotion, displayed for a negotiating purpose? Answering this question is naturally very difficult, and will be a matter of profoundly personal, subjective judgement. It is therefore important to be clear that the notion of AS is very much an interpretivist construct, and that this paper is and perhaps only can be concerned with perceptions of its presence.

The social-functional perspective outlined above therefore foregrounds the ways in which emotions are sometimes perceived to serve the function of co-ordinating, guiding and accomplishing interactive exchanges - as such, they may be described as "other-directed, intentional... communicative acts that organise social interactions" (ibid p.13). This 
understanding provides a useful basis for the study, and has been applied in a number of fields, from game-theoretic analysis (Schelling 1960) to sociology, where Ahmed $(2004,119)$ defends its contribution:

"Rather than seeing emotions as psychological dispositions, we need to consider how they work, in concrete and particular ways, to mediate the relationship between the psychic and the social, and between the individual and the collective."

This understanding is particularly useful since it highlights the need to look beyond individual psychology and personality to focus on the social situatedness of behaviour in order to illuminate contextual contours more sharply. Bloch $(2012,7)$ supports this position on emotions, which, she argues, "highlights the role of social and cultural factors in their development and display." In her examination of power relations in HE, she explores the ways in which emotions are embedded in patterns of power relations. Her study utilises Clark's (1990) theory of emotional micro-politics to illustrate how emotions can be deployed as a positioning tool to negotiate status hierarchies in competitive academic environments.

There are in fact a growing number of studies attracted to the role of emotions in educational contexts (e.g Beard, Clegg and Smith 2007, Christie et al 2008, Gillies 2011), and this increase in educational interest may in itself be symptomatic of what Mestrovic (1997) has described as 'post-emotional society' - a society increasingly characterised by an ethos of and interest in emotionality, where we attach more importance to all emotional matters. A brief examination of such studies is useful at this point, given that AS relies on emotional display in social contexts.

Fairly recently, MacDonald (2014) has related an expansion of emotionality to growing narcissistic tendencies in late-modern society, where social media, self-promoting and individualist values have converged to create stronger needs to connect by means of 
emotional exchange - echoing Giddens' (1992) ideas on the dis-embedded nature of modern life and the need for new modes of connection. MacDonald additionally - and perhaps somewhat controversially - argues that widespread indulgent parenting (p.146) has moulded a generation with unrealistically high demands for emotional attention. As a result, growing emotional frustrations and vulnerabilities ensue, ideas which have again been noted by a number of recent commentators on education, like Twenge and Campbell (2010), who contend that the competitive nature of modern life has exacerbated emotional tendencies and vulnerabilities among young people. These studies are interesting because they link growing perceptions and invocations of student vulnerability with "an increasingly psycho-emotional emphasis” in HE (Ecclestone 2017, 7). 'Vulnerability creep,' as Ecclestone terms it, has become "a powerful and highly normative cultural metaphor" (p.1). One consequence of this, she argues, is the creation of an educational climate that is highly receptive to discourses and constructions of emotional vulnerability and anxiety.

There is certainly no shortage of studies that support Ecclestone's assertion. O'Gorman for one (2015) suggests "the modern university is a breeding ground for worry," while LesnickOberstein (2015) discusses how "unprecedented levels of anxiety and stress among ...students abound, with 'obedient' students expecting and even demanding, hoop-jumping, box-ticking and bean-counting, often terrified by anything new, different or difficult." Outside the UK, Miller's (2013) study presents evidence that $90 \%$ of Canadian university students struggle routinely with anxiety, while Alabsi, Bobryshev and Naggar $(2013,2)$ comment on record levels of uptake of university counselling services in the USA. Davis Hanson's comments further echo constructions of emotional vulnerability:

"Too often, universities emulate greenhouses where fragile adults are coddled as if they were hothouse orchids." (Davis Hanson 2015). 
Focussing on such issues in Northern Europe, Berg, Huijbens and Larsen (2016) suggest that universities are actively complicit in the production of the anxieties referred to above. Their argument focuses on the ways in which "the neo-liberalization of Higher Education, instantiated via an ethos of economic efficiency and intense competition" produces fears which operate particularly powerfully "in both the affective and somatic registers through constant feelings of anxiety (p.8)". Lingard and Lewis (2016) describe neoliberalism as the currently dominant global political ideology, with its prioritisation of market values, competitive mechanisms and principles of New Public Management (NPM), now commonplace across HE systems. Budd (2018) also discusses how the economic logic underpinning neoliberalism has become a strong influence on universities world-wide, steering policy on students, funding and governance. However, he acknowledges differences in the degree to which such thinking has gained traction in different parts of Europe, contrasting in particular a German HE landscape more resistant to knowledge economy values and systems with a more receptive English context. Returning to Berg, Huijbens and Larsen's (2016) study, the authors extend their argument by suggesting that the situation they describe may not simply arise as an unfortunate consequence of neo-liberal rationality - it may even be intended, "purposely created to operate on minds and bodies as a disciplinary practice" (p.8) to serve market and customer interests.

Echoing these studies and also Ecclestone's comments on 'vulnerability creep' above, Brown (2014) encapsulates these ideas in her reference to the current 'vulnerability zeitgeist' - a cultural climate which unites broader tendencies towards greater emotionality with a trend towards more conspicuous invocations of victimhood. Fox $(2016,26)$ suggests these behaviours have now become "a currency for attention, resources and even power," ideas which Furedi (2017) explores specifically in the context of higher education. He too picks up on a university climate characterised more and more by a sensibility that celebrates "the 
display of fragility" (p.17); in such a climate, he argues, such displays will benefit studentconsumers since they may be rewarded with the currency, attention, resources and concessions that Fox refers to, and all the more so in a climate where students' satisfaction is ever more monitored, measured and prioritised. In this context, Furedi refers to "the weaponisation of emotions" (p.28) - using emotions as a forceful strategy for gaining benefit - and in doing so, highlights that emotions can be used as powerful bargaining mechanisms, or indeed as a form of affective strategizing - the idea at the heart of this paper.

Clearly, some of the matters and perspectives under discussion here will divide scholarly opinion and reaction - given the emotive nature of the topic itself, this seems somewhat inevitable. It is important to state, however, that the intention of this paper is not to set up a binary heuristic between a superior, rational, unemotional academy on the one hand and an inferior, emotionalised equivalent on the other. Leathwood and Hey (2009) have been particularly vocal in their criticism of studies which they argue rely on these oppositional stances. The intention here is simply to produce more detailed insights into a particular form of emotionalised behaviour that may for some be negatively connoted; this does not, however, imply a more generalised negative view of emotionality, which must of course be recognised as a positively powerful force in many aspects of learning and education (Gilmore and Anderson 2016). Nor does it imply that students' experience of university is not at times genuinely accompanied by emotional difficulties. At this juncture, a more detailed examination of the research approach adopted will be offered.

\section{Research Context and Design}

As mentioned in the introduction, the aim of the study was to extend previous research carried out by the author based on staff perspectives at one UK university. It is hoped that the inclusion of staff insights from different countries will provide some indication of the 
institutional or even national specificity of the phenomenon under discussion - in other words, that the cross-national approach will contribute to our understanding of the extent to which perceptions of AS are influenced by cultural context. Morris and Keltner $(2006,35)$ identify that "there is a great deal of interest among negotiation researchers in the role of culture" given the potential for differing social norms surrounding emotion and emotional display to result in different behavioural enactments. However, the aim here was not to capture a precise spatial measure of behavioural reach, but more to examine commonalities and differences in the ways teaching staff perceive, understand and account for such behaviour. Barry, Smithey Fulmer and Van Kleef $(2004,88)$ suggest that such endeavours can be best accommodated by "more qualitative and ethnographic methods that tap rich description from participants in contextualised negotiation encounters."

To this end, the study adopted a small-scale survey approach, focussing on the views of academic teaching staff working in (teacher) education departments in three universities. This purposive sampling strategy was an important consideration aiming to facilitate trustworthy comparisons. Table 1 below offers an overview of sample composition:

Table 1: sample characteristics

\begin{tabular}{|l|l|l|l|}
\hline Country & Staff ages & Gender & Levels taught \\
\hline Swedish University & $31-40: 1$ & $\mathrm{M}-7$ & Undergraduate -2 \\
(15 respondents) & $41-50: 4$ & $\mathrm{~F}-8$ & Post-graduate -4 \\
& $50+: 10$ & & Both -9 \\
\hline Dutch University & $23-30: 1$ & $\mathrm{M}-5$ & Undergraduate -10 \\
(16 respondents) & $31-40: 2$ & $\mathrm{~F}-11$ & Post-graduate -1 \\
& $41-50: 4$ & & Both -5 \\
& $50+: 9$ & & \\
\hline English University & $23-30: 1$ & $\mathrm{M}-5$ & Undergraduate -2 \\
(12 respondents) & $31-40: 5$ & $\mathrm{~F}-7$ & Post-graduate -1 \\
& $41: 50: 3$ & & Both -9 \\
& $50+: 3$ & & \\
\hline
\end{tabular}


The three national settings were chosen for a number of reasons. All three share the geographical similarity of being located in Northern Europe, and as (current!) members of the European Union, operate broadly similar HE policies, one key difference relating to fee structures. Annual fees of $€ 1,700$ apply in the Netherlands, compared to around $£ 9,250$ in England and none in Sweden, where modest registration charges apply each semester (The Complete University Guide 2016). Though there is no intention here to suggest that the three settings are culturally and socially homogenous, there are arguably some similarities in these respects. Furthermore, the Netherlands and Sweden are noted for high levels of English language competence (Hoffmann 2000), and this factor was an important research consideration, given the need for respondents to be able to express personal views on complex issues of staff-student relationships. All three participating universities are large, urban institutions catering for diverse student constituencies and subject areas at both undergraduate and post-graduate levels.

Colleagues at each institution distributed information about the study via staff networks. In the end, 43 participants volunteered to complete anonymous on-line questionnaires, consisting of 16 closed and open-ended items structured around Bartram's (2015) analytical framework (more detail is provided in the findings section below). Questions consisted of several types - some capturing categorical detail, while others were based on a mixture of agreement/item selection/open commentary on various aspects of students' emotional bargaining. Although this method cannot be regarded as matching the above appeal for ethnographic enquiry, its strong focus on inviting respondents to share and expand on their views, thoughts and opinions does reflect the desire for rich, qualitative data. The distant/online nature of the method could be criticised as perhaps limiting participants' inclination to respond expansively; however, as Roberts and Allen (2015) discuss, online surveys are often effective ways to address certain ethical considerations such as privacy and 
anonymity, particularly when the issues under investigation are deeply personal and potentially sensitive, and data quality and trustworthiness may thus be enhanced as a result.

In nearly all cases in fact, the open questions generated a wealth of rich data with respondents volunteering highly detailed thoughts and opinions. Analysis of these latter type questions was based on a system of thematic coding and clustering to categorise the views expressed and the themes captured within them. Quotations have been included verbatim and uncorrected, and for the purposes of abbreviation, S, NL and E are used in places below to represent Swedish, Dutch and English respondents as appropriate. It should also be noted that the use of numbers in the tables below is purely for indicative reasons - the intention is simply to provide some numerical sense of emphasis and frequency; the limitations of such numbers in a small-scale study of this kind is of course acknowledged.

\section{Findings from the Study}

As mentioned above, this enquiry drew on Bartram's study (2015), which explored three key dimensions: AS-behavioural contexts (the emotional 'stories' which staff perceived students to draw on); motives (the perceived objectives of the emotional bargaining); and causes (lecturers' reflections on the potential drivers of AS). This paper adds a fourth component staff views on potential solutions. The findings will thus be structured around these four elements.

\section{Contexts}

Firstly, the majority of respondents in all three settings agreed that the students they encounter do make strategic use of emotion (Barry, 1999) - all English respondents agreed, compared to 10/15 Swedish and 12/16 Dutch participants (the others mostly expressed 
ambivalence - only 2 (1 NL, $1 \mathrm{~S})$ expressed actual disagreement). The following examples typify the responses:

"This sort of emotional leverage is just a normal university day-to-day thing for me." (English respondent)

"I think many students today use emotions as a sort of blackmail." (Dutch respondent)

"In my experience, this behaviour is very frequently seen." (Swedish respondent)

As to whether AS behaviours were perceived to constitute a growing tendency, differences were more pronounced; 11 English respondents felt this to be true, compared to only 5 Swedish and 6 Dutch, the others mostly expressing uncertainty. As for the 'emotional scenarios' underpinning the students' AS-behaviours, table 2 presents the numbers of staff agreeing with the contexts identified by Bartram (2015), reflecting co-incidentally the same rankings. As previously stated, numbers are only used here to present a tentative indication of relative emphases within the data. A selection of commonly used vocabulary items added by the respondents have also been included for the purposes of illustration; as shown, constructions of student vulnerability (Ecclestone, 2017) appear central in the contexts selected and language used.

Table 2: 'emotional contexts' drawn on by students

\begin{tabular}{|c|l|l|}
\hline Emotional scenario categories & Numbers agreeing & $\begin{array}{l}\text { Example vocabulary items } \\
\text { volunteered }\end{array}$ \\
\hline 1. Personal anxieties & $41(14 \mathrm{~S}, 15 \mathrm{NL}, 12 \mathrm{E})$ & $\begin{array}{l}\text { scared, too much pressure, } \\
\text { coping difficulties, stressed, } \\
\text { relationship struggles }\end{array}$ \\
\hline $\begin{array}{l}\text { 2. Family-related } \\
\text { difficulties }\end{array}$ & $30(7 \mathrm{~S}, 11 \mathrm{NL}, 12 \mathrm{E})$ & $\begin{array}{l}\text { divorce, parental illness, } \\
\text { family deaths }\end{array}$ \\
\hline 3. Mental health issues & $14(3 \mathrm{~S}, 7 \mathrm{NL}, 4 \mathrm{E})$ & $\begin{array}{l}\text { mental strain, schizophrenia, } \\
\text { depression }\end{array}$ \\
\hline 4. Criminal activities & $1(\mathrm{E})$ & police trouble \\
\hline
\end{tabular}




\section{Motives}

As for the motives staff perceived to lie behind the emotional bargaining, many respondents selected several of the items given (the option to provide additional motives prompted no responses, as was the case with the emotional contexts discussed above). All respondents expressed agreement with at least one motive, providing thus support for the goaldirected/social-functional approach to emotion underpinning the enquiry (cf. Morris and Keltner 2006) and Bartram's (2015) study which revealed emotional bargaining as a strategy for securing academic advantage and concessions. Table 3 offers an overview of agreement and rankings:

Table 3: student motives

\begin{tabular}{|c|l|}
\hline Perceived motives & Numbers agreeing \\
\hline 1. Extensions & $26(8 \mathrm{~S}, 12 \mathrm{NL}, 6 \mathrm{E})$ \\
\hline 2. Need for attention & $25(\mathrm{~S} 6, \mathrm{NL} 13,6 \mathrm{E})$ \\
\hline 3. Higher grades & $24(7 \mathrm{~S}, 5 \mathrm{NL}, 12 \mathrm{E})$ \\
\hline 4. Special consideration & $23(4 \mathrm{~S}, 10 \mathrm{NL}, 9 \mathrm{E})$ \\
\hline 5. Extra tutorials & $11(3 \mathrm{~S}, 5 \mathrm{NL}, 5 \mathrm{E})$ \\
\hline 6. Allocation of different tutor & $6(2 \mathrm{~S}, 1 \mathrm{NL}, 3 \mathrm{E})$ \\
\hline
\end{tabular}

Respondents were invited to discuss their views further here, and several provided instances and details which illuminated many of the above motives, such as the following remarks describing a perceived strategic approach to negotiating additional time for assignment completion:

"A student took extenuating circumstances for a family bereavement because they were so distraught, but did so retrospectively, waiting until the taught content and tutorials for the research project were complete. The student then took a leave of 
absence for a year stating the bereavement but wanted to know if the project structure would alter in between. The student then mentioned the intention to work on the project during the leave of absence. It appeared to me to be a strategic effort to gain the most possible time to maximise the potential work on the project." (English respondent)

Several comments referred to instances that highlighted a therapeutic need for attention (cf. Ecclestone and Brunila 2015), and the accompanying emotional demands this makes on staff:

"Last semester, I was offering module tutorials (in the form of workshops). I had 2 students (mature learners-friends/white 40s) from my part-time evening group attend this session. They discussed the module briefly and spent the rest of the time talking about their work/ personal problems. During the discussion they were conscious of the fact this was not entirely appropriate. However, despite being apologetic about this, they seemed to be relaxed enough to continue to talk. At one point, one of the students mentioned how therapeutic this was. As a lecturer, I did mention the various support tools we offer at the university. However, I sensed they were just comfortable in talking to someone they knew and seemed to be comfortable with. As pleasant as the discussion was, I certainly felt I needed to talk to someone after- as it was so intense!" (English respondent)

There were also comments from staff across the three settings that highlighted - and attempted to explain - why certain students sometimes engaged in AS-behaviours. The following example once again echoes Fox (2016) and also Furedi's (2017) reference to the weaponisation of emotions:

"I have met a few dyslexic students that use their diagnosis as a leverage beyond the scope of their condition - sometimes using emotive arguments. This becomes 
particularly when I swiftly grant them extended deadlines etc in line with their particular diagnosis and the local regulations. Sometimes they keep a sort of bargaining mode even when their first request is granted, almost as a default mode. (However, this could possibly also be attributed to a conditioning process, where they always have had to struggle to get what is within their rights.)" (Swedish participant)

\section{Causes}

This comment is a useful stepping stone to an examination of perspectives on the drivers of AS-behaviours. Once again, staff were invited to express agreement or otherwise with the factors identified in Bartram's (2015) study, and the results are tabulated below:

Table 4: Causal factors

\begin{tabular}{|l|c|}
\hline 'Causal' factors & Numbers agreeing \\
\hline 1 The students themselves & $30(7 \mathrm{~S}, 12 \mathrm{NL}, 11 \mathrm{E})$ \\
\hline 2 The university system & $24(8 \mathrm{~S}, 5 \mathrm{NL}, 11 \mathrm{E})$ \\
\hline 3 University assessment & $22(8 \mathrm{~S}, 9 \mathrm{NL}, 5 \mathrm{E})$ \\
\hline 3 Wider society & $22(7 \mathrm{~S}, 7 \mathrm{NL}, 8 \mathrm{E})$ \\
\hline 4 The school system & $17(5 \mathrm{~S}, 6 \mathrm{NL}, 6 \mathrm{E})$ \\
\hline
\end{tabular}

Those who saw student-related factors as behavioural drivers used a diverse and sometimes contradictory set of descriptors relating to age (younger/more mature); gender (only females mentioned); status (non-traditional/international/low attenders/those with additional needs); personality (individualistic/troubled); and student deficits (lacking motivation, academic ability or resilience/ poor time and stress management/ unable to deal with workload). No uniform pattern emerged across the three sub-sets, with staff views in each setting reflecting equally wide-ranging understandings. Such diversity of explanations could arguably suggest that background and personal characteristics are less influential in creating AS-behaviours than social context (Ahmed, 2004). 
The university system and assessment practices in particular were regarded as complicit in engendering AS-behaviours, though this time a smaller set of common factors were identified across the sub-samples. A lack of clarity in relation to important university procedures was singled out by several respondents in each country. Swedish participants commented on "unclear assessment guidelines and regulations, together with poorly designed courses and modules," and again on insufficiently clear policies on supporting students with additional needs:

"This makes staff unsecure about formal rights and limits thereof, making them susceptible to emotional bargaining (and backlashing, blame-the-student reactions as well)."

Several Dutch respondents echoed similar concerns about procedural clarity, consistency and communication:

"We are not always applying procedures in place transparently, e.g. coming back on decision re progression in view of sob stories. Sets bad precedent. Also not always good exchange of information about students, so that all staff deal with students individually and miss the whole picture."

Another commonly identified theme, as noted by two Swedish respondents, concerned "the new public management culture in HE which creates strain on curriculum policy and practice" and "the discussions of employability and marketization," echoing Berg, Huijbens and Larsen (2016). Several Dutch respondents referred to neo-liberal aspects (cf. Budd, 2018) such as "the commodification of HE in Holland - not so bad yet as England" and growing consumerist orientations among students, which meant that emotional bargaining had for some become a new navigational tool or indeed currency (Fox 2016) - "making money is their first aim...study is not their first priority, so they bargain to get through." This theme 
pervaded the English responses, and perhaps unsurprisingly, was often linked to the recent rise in tuition fees - "there is a marked rise in the students as a consumer with the inherent 'customer is always right' attitude - and 'we are paying for this':

"the increase in tuition fees has led not only to consumer practices amongst students but an over eager approach from the university to recruit and retain students, regardless of conduct or working quality. There has been a notable increase in student support services coupled with altered grading criteria whereby students are by large spoon fed information. The culture has increased students' dependence rather than independence."

One Dutch respondent was critical of relaxed admission criteria designed to widen participation and boost recruitment:

"Students in Holland are entitled to try higher education now, and are no longer selected. This has students enter the system that would not have been accepted 10 years ago, and many of them come up short. This is when they have to be 'creative'...."

Other Dutch respondents felt that emotional bargaining had grown as a result of 'a growing impersonal environment and less regular contacts between staff and students' resulting from massification policies. This theme was again strongly echoed in the English responses:

"They come to us for maybe 1 or 2 days a week...it's harder to build a professional relationship when they spend far less time reflecting on what it means to be a student at university level."

One Swedish lecturer felt that 'students do not perceive the student-teacher relation as formal or serious anymore' and that this lack of personal investment reduced inhibitions to engage in 
AS-behaviours. Overall, and across all the 3 sub-samples, there appeared to be a strong perception that neo-liberal policies put in place (Lingard and Lewis, 2016), as one Dutch respondent described it, "because of financial pressures to keep students and have them graduate" had generally led to dominant practices which over-prioritised student support and satisfaction (via institutional targets and evaluative mechanisms) and that these policies and practices were central elements in encouraging emotional bargaining. Again, the English respondents were especially vocal in these respects, though similar sentiments were rehearsed across the sample. Some comments further echo elements of Ecclestone's (2017) discussion of vulnerability creep and perceived pressures to pander to invocations of fragility:

"Students seem to be wrapped round cotton wool sometimes. They are encouraged to always put the emphasis on others in terms of their development. Mid-module evaluations do that (what is the tutor doing /not doing?). If students are not happy with their assessment grades - again, there is a sentiment on whether it was marked properly or the module was taught adequately by the tutor. End module evaluations and course reps encourage this behaviour similarly." (English respondent)

"Support provisions may have a vested interest in responding sympathetically to a student's emotional bargaining approach. Recruitment driven provision may mean that some students use emotional approaches as a survival strategy in a challenging environment." (English respondent)

"The system quite freely allows for extra chances in case of mitigating circumstances, as it wants maximum passes; to have/find/create those circumstances pays off!" (Dutch respondent)

These final remarks, and several others above, serve to highlight the complex role of student assessment in these matters; throughout the responses, there are repeated comments that 
identify student awareness of (institutional) achievement targets and the additional pressures which these apply to the student experience (e.g. "the increased focus on superficial assessments and the increased importance of grades in order to advance" - Swedish respondent). Many staff refer explicitly to their perceptions of growing assessment pressures on students, and how such burdens not only reinforce AS-behaviours and an HE culture focussed on student support and anxiety alleviation (Lesnick-Oberstein 2015), but also the pressures and demands placed on teaching staff:

"The number of students identified with 'stress' or 'anxiety issues' appears to have increased over the years. Special considerations such as different types of assessment, considerate marking, time allowance etc seem sometimes to be too readily given to students in response to emotional behaviour. Students 'emotional bargaining' increases tutors' vulnerability in everyday work." (English respondent)

As table 4 above suggests, there was much agreement that broader social tendencies were additionally responsible for encouraging bargaining behaviour. One Dutch respondent commented that such behaviour "seems to have become normal in society", while another makes a link with pressing credentialist needs "for all kinds of certificates and diplomas in life these days." Overly indulgent parenting styles were mentioned by one Swedish participant (cf. MacDonald 2014), while an English respondent highlighted the potential for social media to facilitate affective strategizing:

"It has become the social norm. Students mirror other students. Social media also facilitates and encourages a quick and faceless transfer of emotion. They can therefore send an email from home which is laden with emotional bargaining with minimal investment." 
Finally, pre-university education was felt by some to play a part in matters, as table 4 indicates, though fewer comments were made in this regard. For one English respondent, "the education system does not promote resilience or student ownership and so students get used to using emotions to cope." A Swedish participant expressed the following view:

"The Swedish school system as a whole leads students to adapt to all kinds of bargaining processes. Anecdotally, I can't count the times when my children came home and a test they had studied hard for was postponed the same day because enough others complained they were stressed and hadn't studied."

\section{Solutions}

Clearly, it appears that many staff members across all three settings perceive emotional bargaining to be a widespread phenomenon, driven by various factors. One question that arises at this juncture is what might be done to address the matter, and staff were therefore invited to offer their views on potential ways forward. Only a minority expressed some despondency in this regard - one Dutch and one Swedish participant felt that the socially ingrained nature of the issue militated against change; another Dutch respondent expressed a similar view, based on what she saw as an intractable cultural/attitudinal shift:

"Students are asked for feedback at every turn now so are perhaps given the impression that they can effect changes in all areas. In 'my day' we fought hard for our place at uni and were grateful to be there and acknowledged our professors knew more/were wiser than we were so we trusted their decisions on our curriculum. I think those days are gone."

For most other respondents, however, a number of more hopeful possibilities were evident. Several suggestions from all three universities related to more concerted efforts to establish 
clarity and improve staff and student familiarity with key policies and procedures (particularly with regard to assessment), thereby reducing the potential for 'negotiation'. One Swedish participant commented:

"Clearer rules and regulations - I think it is actually easy to keep it at a reasonable level by just knowing enough about the formal and bureaucratic parts of the job, and be sure to communicate this clearly. You need to have a clear idea beforehand (not figure it out as you go) what could/should be open for discussion and what not."

while an English respondent stressed the need for "clear and consistent expectations from ALL staff". Two Dutch respondents felt that improved student coaching would be a useful strategy to this end, particularly at induction, but followed up at key points throughout the year. In fact, more effective all-round communication was frequently identified as central in this respect, and several staff in each setting suggested that "more direct teaching contact with students" (Swedish respondent) would be beneficial. All the same, several felt greater efforts to communicate procedural clarity would be ineffective without "tightening up some of the university procedures" (English respondent) themselves, particularly in relation to "mitigating circumstances allowances, this has all become so loose now" (Dutch response), and in some cases, admission policies.

Some staff suggested that given the dominance of neo-liberal ideology in HE (Budd, 2018), little would alter without "rethinking the HE landscape and a radical move away from NPM [new public management] models" (Swedish respondent), and though such views were expressed across all three sub-sets, they were most conspicuous among the English respondents, whose comments were often suggestive of low-trust relationships with management that undermined staff relations and morale, and inappropriately inflated rather 
than managed student expectations. Tuition fees were once again implicated in this perceived malaise:

"Student fees have had an immeasurable impact. Also a willingness on behalf of the university to encourage independent learning and removal of the blame culture attached to lecturers for low attaining students."

"We need a more rigorous and hard line organisational approach which does not bend to student wishes. Abolition of student fees."

"Support from management for staff rather than caving into unrealistic student demands."

"Students should be encouraged to critically reflect on themselves and the types of decisions they make as opposed to being encouraged to find faults in the education system itself. The use of emotion by students is a corrosive force in HE and is certainly (100\%) impacting upon standards. A coping mechanism for staff is to simply give a high grade."

At the same time, there was an acknowledgement that changes in the neo-liberal regimes alluded to are unlikely, and that a simpler way forward may come down to what Clegg and Rowland (2010) describe as kindness in pedagogical practice, encapsulated in the remarks of 2 Dutch respondents below:

"If we show respect, patience and understanding to students - gently nugde them - we can solve this."

"Honest communication and 'true' empathy is the only way to deal with people. This is the right way of working together and through empathy, effective collaboration is achieved." 


\section{Discussion and Conclusions}

At this point, it is worth reflecting on what conclusions arise from the study. Clearly, any claims here need to be considered in light of the enquiry's limitations. As a small-scale survey involving a single - but productive - data collection instrument, conclusions are necessarily tentative and indicative. Selectivity effects must of course also be borne in mind. Nonetheless, it is hoped that purposive sampling, the cross-national angle adopted and the qualitative depth and detail provided have improved the study's trustworthiness and relatability, as well as contributing novel empirical insights to this under-explored field (Smithey Fulmer, Barry and Long 2008). It is also important to stress once again that there is no intention here to judge or trivialise the emotional stresses students may experience during their time at university - the intention has been to explore staff perceptions of students' use of emotions - "whether genuine expressions or strategic displays" (Morris and Keltner 2006, 4).

Firstly, it appears that many of the staff in this survey share broadly similar views, though there are of course differences in emphasis. This commonality may to some degree be a function of the self-selective nature of the sample and potentially similar dispositional tendencies that accompany the shared discipline of education - highlighting thus the usefulness of undertaking further research across different subject areas. All the same, as noted, many staff in this study regard emotional bargaining as a commonly experienced aspect of working life and recognise the weaponisation of emotions in HE that Furedi (2017) refers to. There are also commonalities in the motives perceived behind the behaviour and the factors which drive it. As Bartram $(2010,187)$ suggests, "evidence of phenomena across a range of contexts arguably allows more weight to be attached to certain conclusions given the replication of findings across datasets." As such, the findings here support the socialfunctional theoretical positioning (Morris and Keltner 2006) adopted, and tentatively suggest 
that 'national' culture may be less influential than other factors. Reflecting on these, there is some room to argue that HE policy plays a part in driving students' emotional bargaining, and that this contextual background is important.

In many of the participants' views, this background is characterised by neo-liberal rationality (Budd, 2018) - there are references to common managerialist practices, policies and pressures which prioritise 'customer' satisfaction, the achievement of targets and the measurement of (assessment) outcomes. Such references strongly pervade the English responses in particular - perhaps because, as one of the Dutch respondents suggests ('the commodification of HE in Holland - not so bad yet as in England'), neo-liberal reforms in Holland (and Sweden) have not yet achieved quite the same degree of traction, and tuition fees are significantly lower. One possible interpretation here, and indeed one of this study's key contributions to this field, is that neo-liberal regimes may then be a particularly important factor in engendering emotional bargaining, and that this contextual climate mediates the emotional connection between the psychic and the social, the individual and the collective (Ahmed 2004, 119). In relation to Berg, Huijbens and Larsen's (2016) arguments - the question arises as to the intentionality and desirability of this behaviour within neo-liberalised institutions. Through a neo-liberal lens, AS-related behaviours can perhaps be seen as a useful disciplinary practice which focuses staff/provider attention and energies on optimising customer outcomes and expectations (by achieving some of the objectives identified in table three).

Another conclusion relates to perceptions of 'gaps' - in clarity, consistency, policies and practice. The participants suggest throughout that these create spaces for negotiations and bargaining, particularly in the kind of high-stakes (and in England, high-fees) environment described. As suggested by several of the respondents themselves, a clear recommendation arising from the study is for institutions and departments to consider more effective ways of 
consolidating and standardising staff and student understanding of policies and practices in an attempt to minimise the emergence of such gaps. The study offers innovative evidence that the bargaining opportunities created by these spaces can be further strengthened through emotionalised invocations of vulnerability (Ecclestone 2017) in a climate which is 1) highly receptive to such invocations, characterised by an ethos that 'celebrates' emotional fragility (Furedi 2017); and 2) strongly focused on 'customer-centric' performativity. This focuses attention on such matters as induction programmes for all concerned, and ongoing staff training and reflection. The study also reveals evidence of staff who in some cases are clearly struggling in different ways to adapt to changing student constituencies, new ways of working, new (recruitment/assessment) policies, new ways of supporting students and changes surrounding teaching roles and student expectations. Though some might be inclined to dismiss some of the views above as reactionary or offensive, a more constructive way forward would be for institutions to reflect on the strategies they adopt to support staff in coping with the increased demands and challenges that are placed upon them in the neoliberal HE landscape referred to by some above.

\section{References:}

Ahmed, S. 2004. The Cultural Politics of Emotion. Edinburgh: Edinburgh University Press.

Alabsi, M., Bobryshev, Y. and Naggar, R. 2013. "Perfectionism and Social Anxiety among University Students.” Journal of Psychiatry, 14 (1): 1-8.

Barry, B. 1999. "The Tactical Use of Emotion in Negotiation." Research in Negotiation in Organizations. 7: 93-121.

Barry, B. Smithey Fulmer, I. and Van Kleef, G. 2004. I Laughed, I Cried, I Settled: The Role of Emotion in Negotiation. The Handbook of Negotiation and Culture edited by Michele J. Gelfand and Jeanne M. Brett. Stanford: Stanford University Press. 71-94.

Bartram, B. 2010. Attitudes to Language Learning: Insights from Comparative Education. London: Bloomsbury. 
Bartram, B. 2015. "Emotion as a Student Resource in Higher Education." British Journal of Educational Studies, 63 (1): 67-84.

Beard, C., Clegg, S. and Smith, K. 2007. "Acknowledging the Affective in Higher Education." British Educational Research Journal, 33 (2): 235-252.

Berg, L.D., Huijbens, E.H. and Larsen, H. G. 2016. "Producing Anxiety in the Neoliberal University." The Canadian Geographer, 60 (2): 168-180.

Bloch, C. 2012. Passion and Paranoia: Emotions and the Culture of Emotion in Academia. Farnham: Ashgate.

Brown, K. 2014. Beyond Protection: "The Vulnerable in the Age of Austerity." In M. Harrison and T. Sanders (Eds.) Social Policies and Social Control: New perspectives on the Not-so-big Society (39-52). London: Policy Press.

Budd, R. 2018. Higher Education- From Global Trends to Local Realities. International and Comparative Education: Contemporary Issues and Debates edited by Brendan Bartram. Abingdon: Routledge. 129-142.

Christie, H., Tett, L., Cree, V., Hounsell, J. and McCune, V. 2008. "A Rollercoaster of Confidence and Emotions: Learning to be a University Student". Studies in Higher Education, 33 (5): 567-581.

Clark, C. 1990. "Emotions and Micropolitics in Everyday Life: Some Patterns and Paradoxes of Place." In Kemper, T. D., Research Agendas in the Sociology of Emotions. Albany: State University of New York Press, 303-333.

Clegg, S. and Rowland, S. 2010. "Kindness in Pedagogical Practice and Academic Life." British Journal of Sociology of Education 31 (6): 719-735.

Davis Hanson, V. 2015. “The Modern University Is Failing Students in Every Respect.” National Review, 15/4/15. Available at:

http://www.nationalreview.com/article/416673/modern-university-failing-students-everyrespect-victor-davis-hanson [Accessed 30th May 2016]

Ecclestone, K. 2017. "Changing the Subject of Education? A Critical Evaluation of Vulnerability Creep and its Implications.” Social Policy and Society, 13 (3): 1-14.

Ecclestone, K. and Brunila K. 2015. "Governing Emotionally Vulnerable Subjects and 'Therapisation' of Social Justice.” Pedagogy, Culture and Society, 23 (4): 485-506.

Fox, C. 2016. I Find That Offensive. London: Biteback Publishing.

Furedi, F. 2017. What's Happened to the University? A Sociological Exploration of its Infantilisation. London: Routledge.

Giddens, A. 1992. The Transformation of Intimacy: Sexuality, Love and Eroticism in Modern Societies. Cambridge: Polity. 
Gillies, V. 2011. "Social and Emotional Pedagogies: Critiquing the New Orthodoxy of Emotion in Classroom Behaviour Management." British Journal of Sociology of Education, 32 (2): 185-202.

Gilmore S. and Anderson V. 2016. "The Emotional Turn in Higher Education: a Psychoanalytic Contribution." Teaching in Higher Education, 21 (6): 686-699.

Hagenauer, G., Gläser-Zikuda, M. and Volet, S. 2016. “University Teachers' Perceptions of Appropriate Emotion Display and High-quality Teacher-student Relationships: Similarities and Differences Across Cultural-educational Contexts." Frontline Learning Research, 4 (3): 44-74.

Hoffmann, C. 2000. "The Spread of English and the Growth of Multilingualism with English in Europe." In Cenoz, J. and Jessner, U. (eds), English in Europe: The Acquisition of a Third Language. Clevedon: Multilingual Matters.

Leathwood, C. and Hey, V. 2009. "Gender/ed Discourses and Emotional Sub-texts: Theorising Emotion in UK Higher Education.” Teaching in Higher Education, 14 (4): 429440.

Lesnick-Oberstein, K. 2015. "Let UK universities do what they do best - teaching and research.” Guardian Online, July 6, 2015. Available at:

https://www.theguardian.com/education/2015/jul/06/let-uk-universities-do-what-they-dobest-teaching-and-research. [Accessed 2nd June 2016]

Li, S. and Roloff, M.E. 2006. Strategic Emotion in Negotiation: Cognition, Emotion, and Culture in Riva, G., Anguera, M.T., Wiederhold, B.K. and F. Mantovani (Eds)

Communication to Presence: Cognition, Emotions and Culture towards the Ultimate Communicative Experience. Festschrift in honor of Luigi Anolli..Amsterdam: IOS Press: 169-188.

Lingard, B. and Lewis, S. 2016. Globalization of the Anglo-American Approach to Topdown, Test-based Educational Accountability. Handbook of Human and Social Conditions in Assessment. New York: Routledge: 387-403.

MacDonald, P. 2014. "Narcissism in the Modern World", Psychodynamic Practice, 20 (2): 144-153.

Mestrovic, S. 1997. Postemotional Society. London: SAGE.

Miller, A. 2013. "Canadian Students Feel Stress, Anxiety, Have Suicidal Thoughts, Survey Reveals." The Canadian Press, http://www.theglobeandmail.com/news/national/education/college-university-students-feelstress-anxiety-have-suicidal-thoughts-survey-reveals/article12613742/ [Accessed $8^{\text {th }}$ April $\underline{2016]}$

Morris, M.W and Keltner, D. 2000. "How Emotions Work: the Social Functions of Emotional Expression in Negotiations." Research in Organizational Behaviour, 22: 1-50. 
O'Gorman, F. 2015. "How Academe Breeds Anxiety." The Chronicle of Higher Education, July 12, 2015. http://chronicle.com/article/How-Academe-Breeds-Anxiety/231441 [Accessed 14th April 2016]

Roberts, L. and Allen, P. 2015. "Exploring Ethical Issues Associated with Using Online Surveys in Educational Research.” Educational Research and Evaluation, 21 (2): 95-108.

Schelling, T. 1960. The Strategy of Conflict. Oxford: Oxford University Press.

Smithey Fulmer, I., Barry, B. and Long, D. A. 2009. "Lying and Smiling: Informational and Emotional Deception in Negotiation.” Journal of Business Ethics, 88: 691-709

The Complete University Guide. 2016. Available at:

http://www.thecompleteuniversityguide.co.uk/international/europe [Accessed 7th June 2016]

Twenge, J.M and Campbell, W.K. 2010. The Narcissism Epidemic: Living in the Age of Entitlement. New York: Free Press.

Van Kleef, G., Homan, A. and Cheshin, A. 2012. "Emotional Influence at Work: Take it EASI.” Organizational Psychology Review, 2 (4): 311-339. 